\title{
OPEN Real-time monitoring of Arundo donax response to saline stress through the application of in vivo sensing technology
}

\author{
Janni Michela ${ }^{1,2 \bowtie}$, Cocozza Claudia ${ }^{3 凶}$, Brilli Federico ${ }^{4}$, Pignattelli Sara ${ }^{4,7}$, Vurro Filippo ${ }^{1}$, \\ Coppede Nicola ${ }^{1}$, Bettelli Manuele ${ }^{1}$, Calestani Davide ${ }^{1}$, Francesco Loreto $^{5,6}$ \& \\ Andrea Zappettini ${ }^{1}$
}

One of the main impacts of climate change on agriculture production is the dramatic increase of saline $\left(\mathrm{Na}^{+}\right)$content in substrate, that will impair crop performance and productivity. Here we demonstrate how the application of smart technologies such as an in vivo sensor, termed bioristor, allows to continuously monitor in real-time the dynamic changes of ion concentration in the sap of Arundo donax L. (common name giant reed or giant cane), when exposed to a progressive salinity stress. Data collected in vivo by bioristor sensors inserted at two different heights into $A$. donax stems enabled us to detect the early phases of stress response upon increasing salinity. Indeed, the continuous timeseries of data recorded by the bioristor returned a specific signal which correlated with $\mathrm{Na}^{+}$content in leaves of $\mathrm{Na}$-stressed plants, opening a new perspective for its application as a tool for in vivo plant phenotyping and selection of genotypes more suitable for the exploitation of saline soils.

Soil salinity is a recurrent and adverse environmental stressor that impairs crop growth and productivity, and negatively affects food security ${ }^{1,2}$. The area of saline soil is as large as 397 million ha ${ }^{3}$. It is well established that a high soil salinity impacts on the survival of many plant species, especially halophytes ${ }^{4}$. To address lands recovery from salinity by promoting alternative land uses, renewable alternative energy sources is steadily rising, thus plant species (genotypes) resistant to salinity must be identified ${ }^{5}$. Salinity may be tolerated by plants through different strategies involving either 'tissue tolerance', where toxic ions are compartmentalized into specific tissues, cells and subcellular organelles, or 'toxic ion exclusion', where plant survival is maintained by fast translocation of $\mathrm{Na}^{+}$out of the plant to avoid excessive accumulation into the shoot apical meristems ${ }^{6-8}$.

So far, a wide range of physiological, biochemical and molecular analyses have been employed to detect and study salinity stress and how it adversely affects plant growth and performance ${ }^{2,9-14}$. However, these methods, rely on destructive assays, on indirect measurement or on digital imaging, and thus only allow indirect access to the effects of saline stress on plants performances ${ }^{8,15-19}$. The electrical impedance spectroscopy (EIS) is proposed to study the behavior and properties of cell membranes in plants to investigate the plant tolerance to different abiotic stress, such as drought ${ }^{20-23}$ and salt stress ${ }^{24}$. Because of the passive electrical properties, plant tissue impedance is related to cellular ionic content, membrane structures and viscosity ${ }^{23}$ and is determined by the observation of the tissue electrical response through two external electrodes placed on both side of the sample leaves ${ }^{24,25}$.

The availability of a novel technology able to monitor continuously and in vivo plant responses to environmental constraints, and to be applicable in open field, would allow us to early identify and follow the onset of mechanisms triggered within plants by the occurrence of salinity stress. Recently, a novel sensor has been

\footnotetext{
${ }^{1}$ National Research Council of Italy, Institute of Materials for Electronics and Magnetism (IMEM), National Research Council (CNR), Parco Area delle Scienze 37/A, 43124 Parma, Italy. ${ }^{2}$ National Research Council of Italy, Institute of Bioscience and Bioresources (IBBR), National Research Council (CNR), Via Amendola 165/A, 70126 Bari, Italy. ${ }^{3}$ Department of Agriculture, Food, Environment and Forestry (DAGRI), University of Florence, via San Bonaventura 13, 50145 Florence, Italy. ${ }^{4}$ National Research Council of Italy, Institute for the Sustainable Plant Protection (CNR - IPSP), Via Madonna del Piano 10, 50019 Sesto Fiorentino, Italy. ${ }^{5}$ National Research Council of Italy - Department of Biology, Agriculture and Food Sciences, (CNR-DISBA), P. Le Aldo Moro, 00185 Roma, Italy. ${ }^{6}$ Department of Biology, University of Naples Federico II, Naples, Italy. ${ }^{7}$ Laboratory of Environmental and Life Sciences, University of Nova Gorica, Vipavska cesta 13, 5000 Rožna Dolina, Nova Gorica, Slovenia. ${ }^{\circledR}$ email: michela.janni@imem.cnr.it; claudia.cocozza@unifi.it
} 


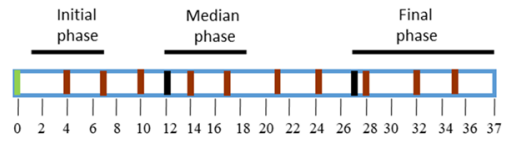

A)

dpi

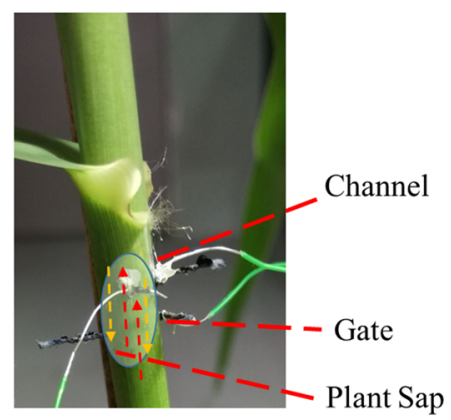

B)



Bioristor application in Arundo donax and read-out system

Figure 1. Real-time monitoring of salinity response in A. donax with bioristor. (A) Experimental set-up: the green block indicates the insertion of sensors into $A$. donax stem; brown lines indicate saline treatments $(200 \mathrm{mM} \mathrm{NaCl})$ and the black lines correspond to the sensor maintenance. Destructive measurements were performed in the initial phase at $1 \mathrm{dpi}$, in the median phase at $18 \mathrm{dpi}$ and in the finale phase at $24 \mathrm{dpi}$; (B) A detailed view of a biostor inserted into A. donax stem. Dashed yellow and red lines represent the sap movement directions. (C) Scheme of the bioristor installation and function principle into A. donax plants; two sensors were inserted: one between the 2nd and the 3rd leaf (apical sensor, AS), and a second one between the 5th and 6th leaf (basal sensor, BS).

developed to continuously and in in vivo monitor variations of the plant sap ion composition and concentration ${ }^{26}$. This device, named 'bioristor', is an organic electrochemical transistor (OECTs) realized on a textile fiber and integrated into the plant stem. An organic electrochemical transistor (OECT) is made of a conducting polymer film in contact with an electrolyte and a gate electrode immersed in $\mathrm{it}^{27}$. The working principle of an OECT is based on doping-state changes in the semiconductor channel material due to electrolyte-ion injections which modify the electrical conductivity ${ }^{28}$.

A positive input voltage at the gate electrode modulates the channel current by pushing cations from the electrolyte into the PEDOT: PSS matrix modifying the channel conductivity ${ }^{29}$. The bioristor was proven to be effective in determining the cation (i.e. $\mathrm{Na}^{+}, \mathrm{K}^{+}, \mathrm{Ca}^{2+}, \mathrm{Mg}^{2+}$ ) concentration of water and other organic liquids ${ }^{30-33}$ in the range of $10^{-1}-10^{-4} \mathrm{M}$ with the limitation of not being selective for a single cation ${ }^{30-33}$. In addition, the pioneering application of bioristor in dicotyledonous plant species, such as tomato, successfully allowed detection of changes occurring in the plant sap composition following the day/night circadian cycle ${ }^{26}$, as well as early detection of plant stress conditions under drought ${ }^{33}$. The correlations among bioristor sensor response, changes in relative humidity, and vapour pressure deficit have been recently demonstrated, proposing the bioristor as a novel sensor to improve water use efficiency ${ }^{34}$.

Here, we report on the application of the bioristor to monitor Arundo donax plants challenged with a severe salt stress (Fig. 1). A. donax is a perennial monocot species responsive to salt treatment ${ }^{14}$, and a promising crop for both bioenergy and biomass feedstock ${ }^{35}$. In companion studies, $A$. donax showed ability to cope salinity coupled with high $\mathrm{P}$ concentration by revealing efficient stomatal regulation ${ }^{14}$ and by enhancing biosynthesis of antioxidants ${ }^{26}$. In companion studies, $A$. donax showed ability to grown in saline soil ${ }^{14}$ by revealing efficient stomatal regulation ${ }^{14}$ and by enhancing biosynthesis of antioxidants ${ }^{26}$. Indeed, $A$. donax shows the spread in altered stream hydrology or sea-level rise, namely fields dominated by saline soils ${ }^{10}$. In particular, the objectives of this work were: (1) to investigate the bioristor sensitivity to the overall salinity which is mostly controlled by the Na concentration in the plant sap; (2) to evaluate whether the bioristor can be used as a rapid and nondestructive method for early detection of salt stress; (3) to increase knowledge of the mechanisms employed by A. donax to withstand saline stress.

\section{Results}

In this study, the bioristor was applied to investigate changes in A. donax sap composition to track in vivo and in real-time the plant's response triggered by the application of severe saline stress conditions. The bioristor confirmed its ability to monitor daily variation of the sensor response (R) in A. donax as previously reported in tomato ${ }^{26}$, with $\mathrm{R}$ values increasing during the night and rapidly decreasing during the day (Supplementary Fig. 1) both in the apical sensor (AS) and in the basal sensor (BS). 

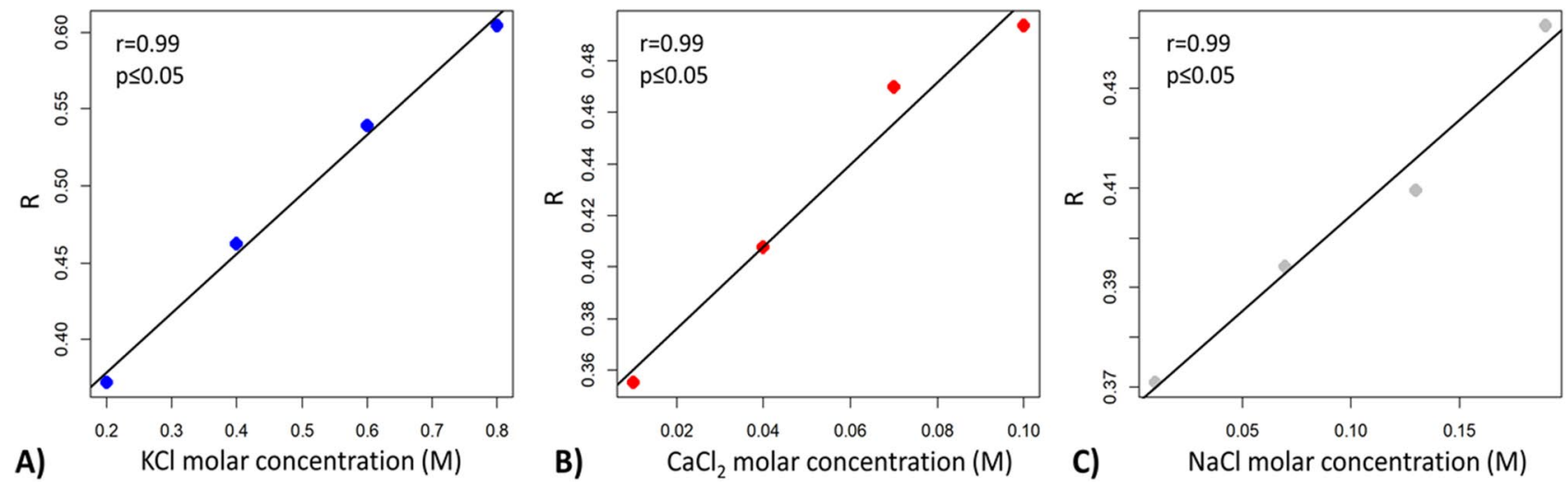

Figure 2. Scatter plots of the correlation between the Sensor Response (R) measured in vivo in the plant sap at $1 \mathrm{~V}$ and the molar concentration of $(\mathbf{A}) \mathrm{K}^{+}$(blue dots); (B) $\mathrm{Ca}^{2+}$ (red dots); (C) $\mathrm{Na}^{+}$(grey dots) measured in the leaves of A. donax.

The transfer characteristic of bioristor was verified, in vitro, for $\mathrm{Ca}^{2+}, \mathrm{K}^{+}$, and $\mathrm{Na}^{+}$(Supplementary Fig. 2) using concentrations within the range found in the leaves during the saline stress experiments (see Table 2), demonstrating the possibility to detect through bioristor small changes in the salt related ions concentration. The in vivo test on $A$. donax plants confirmed this property of the bioristor. The linear response of the sensor measured continuously in the plant sap versus the ions concentration measured in Arundo leaves (Fig. 2) showed that the bioristor was able to detect changes in all tested ions.

To gain more accurate results on the trend of the bioristor response upon saline treatment, the NR (Normalized Response) parameter allowed us to overcome the disturbance due to day/night oscillation. In the initial phase of the experiment (1-7 dpi, days post insertion), the NR of the BS showed a rapid and consistent increase $(60 \%)$ after addition of $\mathrm{Na}^{+}(3 \mathrm{dpi}$, Fig. $3 \mathrm{~A})$ up to a maximum recorded at $6 \mathrm{dpi}(p \leq 0.001$, Fig. $3 \mathrm{~A}$, Table 1$)$. Whereas the AS showed a constant and lower response than BS up to $4 \mathrm{dpi}$ (Fig. 3A). In the median phase of the experiment (13-19 dpi; Fig. 3B, Table 1), the NR value of BS significantly increased up to 15.5 dpi $(p \leq 0.001)$, and then decreased up to $17 \mathrm{dpi}$, suggesting first an ongoing accumulation and compartmentalization of $\mathrm{Na}^{+}$ in the basal leaves. Upon a new addition of $\mathrm{Na}^{+}$at dpi 17 (the fifth salt supply, see Fig. 1A), NR of AS showed a new and continuous increase $(p \leq 0.001)$ (Fig. 3B). These data collected in vivo are consistent with the observed general decrease in the transpiration rate measured in salt-stressed plants (Fig. 4).

The final phase of the experiment covered dpi 27-37. Early in this phase, a stable NR signal was observed in BS. However, NR of BS increased rapidly after the addition of salt (Fig. 1A) at $32 \mathrm{dpi}$ ( $p \leq 0.001$, Fig. 3C, Table 1). On the other hand, an increase of the NR signal was observed in AS at $28 \mathrm{dpi}$, which was not followed by additional increases after subsequent $\mathrm{Na}^{+}$treatments.

The transpiration rates (TR) measured 18 and 24 dpi in both apical and basal leaves of salt-stressed plants were significantly lower than in control ones (Fig. 4). $\mathrm{Na}^{+}$progressively accumulated in leaves of salt-stressed plants. However, $\mathrm{Na}^{+}$concentration did not show any statistical difference between apical and basal leaves in the median and final phases (Table 2).

PCA was performed by considering the measured variables $\left(\mathrm{Na}^{+}, \mathrm{K}^{+}\right.$and $\mathrm{Ca}^{+2}$ concentration and the total cations concentration and transpiration rate). Of note, to increase the accuracy of the PCA analyses the bioristor's response $\mathrm{R}$ was here considered to allow for the analyses of stressed and control response. Each dot in the diagram (Fig. 5) describes the state of the system measured at specific time points (0, 18, 24 dpi for control plant; $18,24 \mathrm{dpi}$ for stressed plants) for both apical and basal measurement, and the first two components explain $86.8 \%$ of the variance (Fig. 5). The first PC (PC1) explained 54.9\% of the total variance. In particular, the total cations concentration (TCC) and $\mathrm{Na}^{+}, \mathrm{K}^{+}$and $\mathrm{Ca}^{+2}$ concentrations measured in leaves and $\mathrm{R}$ have large positive loading on the PC1 and are positively correlated (Fig. 5). The regularly irrigated controls and the salt-stressed plants are well separated in the biplot indicating the efficacy of the saline treatment.

The analyses of the PCA loading vectors showed a positive and high correlation between $\mathrm{R}$ and $\mathrm{Na}^{+}$concentration measured in leaves and this is confirmed by the multivariate analysis (Figs. 5, 6A), supporting the efficacy of bioristor in revealing in real-time changes in the plant sap cation concentration during the stress. Furthermore, the analyses of the correlation between $\mathrm{R}$ and TR, showed a high and inverse correlation between $\mathrm{R}$ and TR (Fig. 6B) that is recognised as strongly affected by the saline stress (Fig. 6C).

The time course analyses of the ions in the plant leaves showed that $\mathrm{Na}^{+}$increased following the salt treatment and the decreased of $\mathrm{Ca}^{2+}$ concentration in salt-stressed basal leaves in comparison to the control ones, both at medial and final stages of the salt treatment. Furthermore, $\mathrm{K}^{+}$showed an accumulation in apical leaves only in salt stressed plants in the medial stage, whereas $\mathrm{K}^{+}$decreased in apical leaves and increased in basal leaves at the final stage of stress, compared to respective controls (Table 2, Fig. 2).

\section{Discussion}

This study supports the use of $A$. donax as a valuable energy crop, able to grow in saline soils thus promising for the exploitation of marginal land ${ }^{10,36}$. 
A)
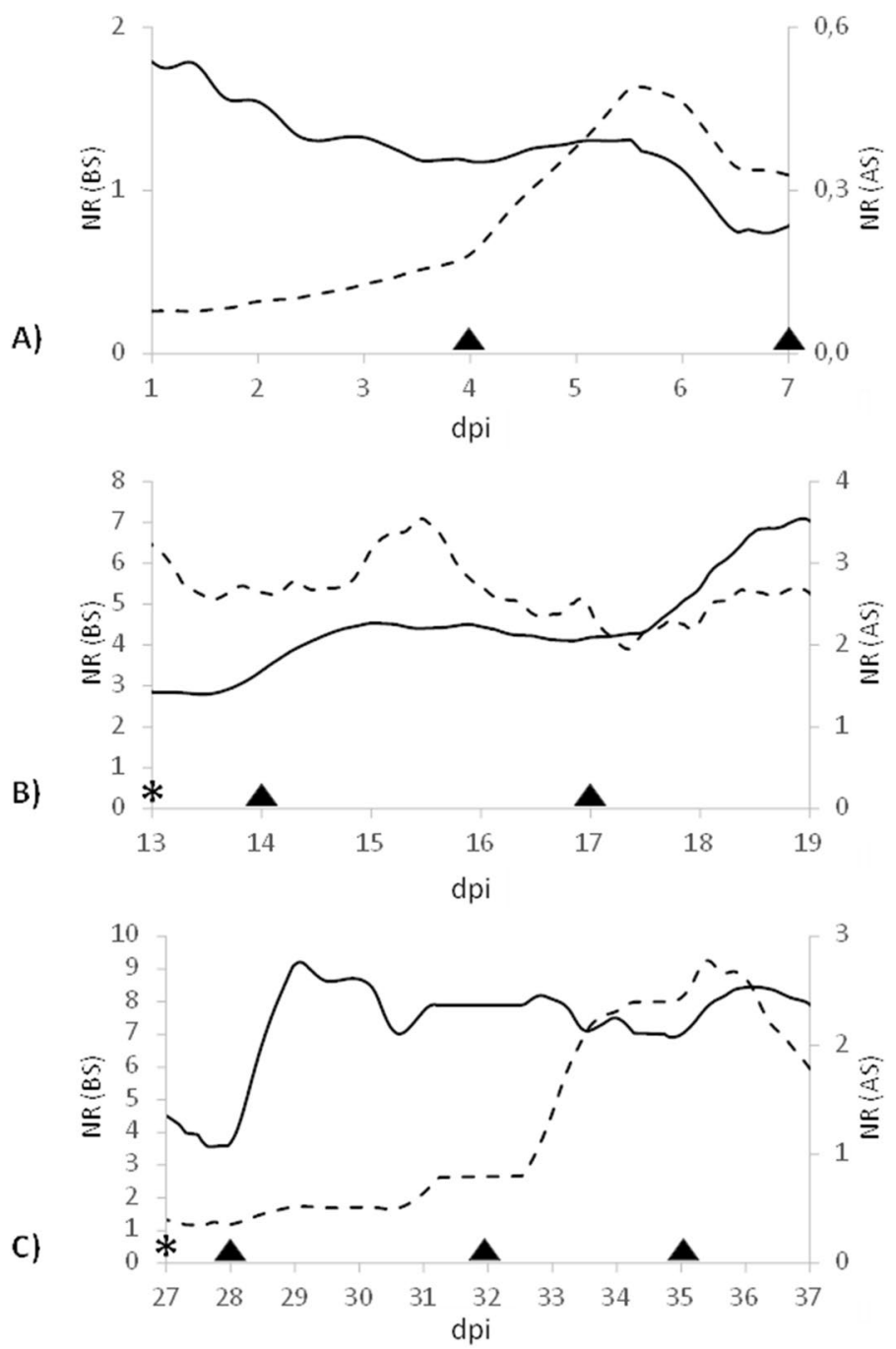

Figure 3. Normalized Sensor Response (NR) of the apical sensor (AS, solid line) and the basal sensor (BS, dashed line) in three different intervals of the experiments: (A) initial phase (1-7 days post sensor installation, dpi); (B) median phase (13-19 dpi); (C) final phase (27-37 dpi). Solid triangles indicate the application of saline treatments. The asterisk indicates the maintenance of the sensor.

\begin{tabular}{|c|c|c|c|c|}
\hline \multirow[b]{2}{*}{ dpi } & & \multicolumn{2}{|l|}{ Sensor response $(\mathrm{R})$} & \\
\hline & & Control & Stress & \\
\hline & & & & p-level (control vs stress) \\
\hline \multirow{3}{*}{0} & Apical leaf & $5.24 \times 10^{-2} \pm 1.72 \times 10^{-3}$ & $2.81 \times 10^{-2} \pm 6.03 \times 10^{-4}$ & n.s \\
\hline & Basal leaf & $3.27 \times 10^{-2} \pm 1.72 \times 10^{-3}$ & $8.52 \times 10^{-3} \pm 6.24 \times 10^{-4}$ & n.s \\
\hline & p-level (apical vs basal) & $* * *$ & $* * *$ & \\
\hline \multirow{3}{*}{18} & Apical leaf & $2.51 \times 10^{-2} \pm 1.17 \times 10^{-3}$ & $4.23 \times 10^{-2} \pm 9.32 \times 10^{-4}$ & $* * *$ \\
\hline & Basal leaf & $1.53 \times 10^{-2} \pm 7.02 \times 10^{-4}$ & $8.07 \times 10^{-2} \pm 1.44 \times 10^{-3}$ & $* * *$ \\
\hline & p-level (apical vs basal) & $* * *$ & $* * *$ & \\
\hline \multirow{3}{*}{24} & Apical leaf & $3.94 \times 10^{-2} \pm 2.70 \times 10^{-3}$ & $1.03 \times 10^{-1} \pm 2.56 \times 10^{-3}$ & $* * *$ \\
\hline & Basal leaf & $4.52 \times 10^{-2} \pm 3.51 \times 10^{-3}$ & $7.72 \times 10^{-2} \pm 2.1 \times 10^{-3}$ & $* * *$ \\
\hline & p-level (apical vs basal) & n.s & $* * *$ & \\
\hline
\end{tabular}

Table 1. Sensor Response (R) of control and salt stressed A. donax plants measured at different times: before the beginning of the experiment ( $0 \mathrm{dpi})$, in the initial phase (18 dpi), and in the median phase ( $24 \mathrm{dpi})$. Values represent the mean of the daily $\mathrm{R}$ value \pm standard errors $(\mathrm{n}=3)$. ANOVA has been used to assess statistical differences between leaves of control and salt-stressed plants $\left({ }^{* *} p \leq 0.001 ;{ }^{* *} p \leq 0.01 ;{ }^{*} p \leq 0.05\right)$. 

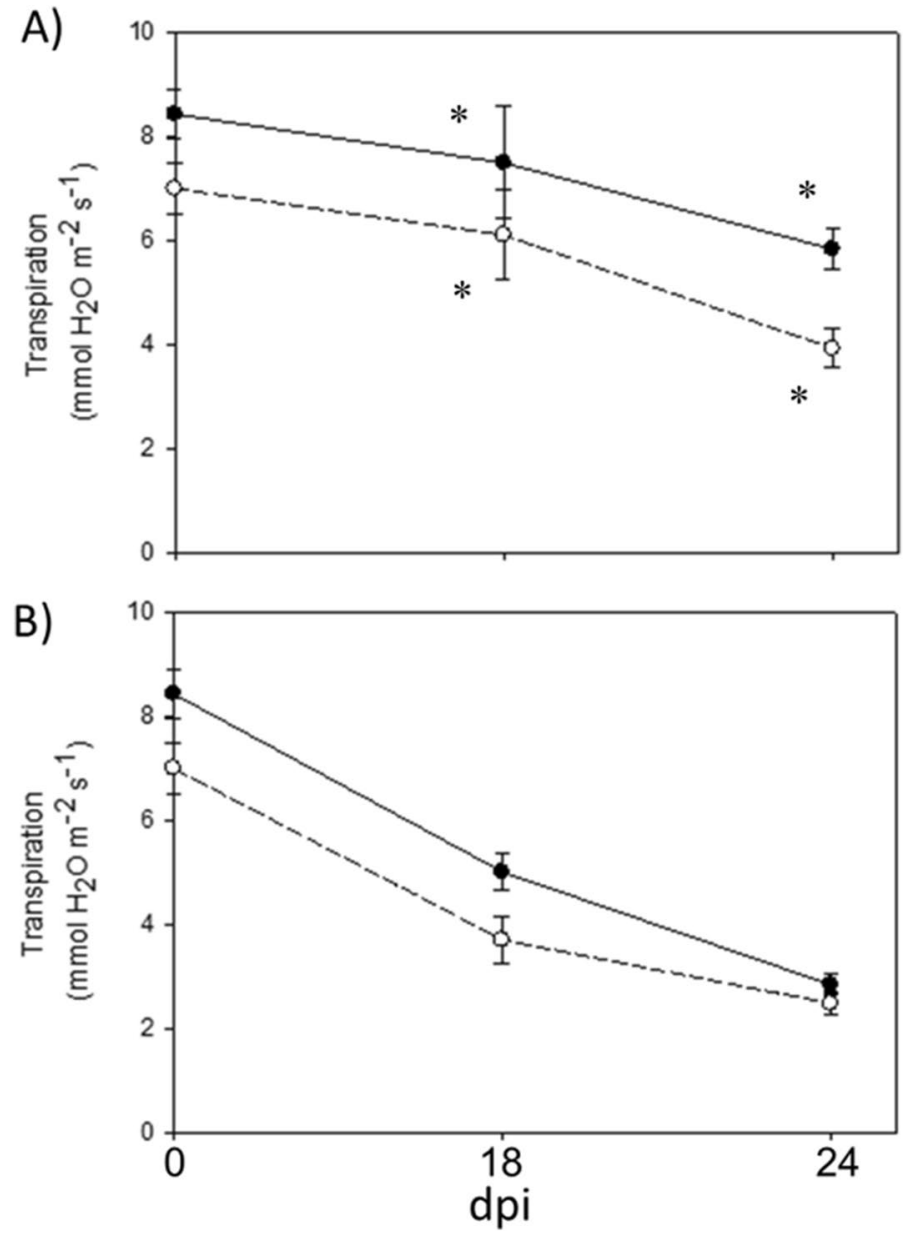

Figure 4. Transpiration rates of control (A) and salt stressed (B) A. donax plants measured at different sampling times: 1, 18 and 24 dpi (see Fig. 3). Black circles indicate measurements collected from the 2nd leaf (apical leaf) and white circles indicate measurements collected form the 5th leaf form the top (basal leaf). Values are means \pm standard errors $(n=4)$. Shapiro-Wilk test was applied to confirm normal distribution of data. Statistically significant differences between means of either apical or basal leaves of control- and salt-stressed plants are indicated by $\left(^{*}\right)(P<0.05)$.

\begin{tabular}{|c|c|c|c|c|c|c|c|c|c|c|c|c|c|}
\hline \multirow[b]{2}{*}{$\mathrm{dpi}$} & & \multicolumn{2}{|l|}{$\mathrm{Na}^{+}\left(\mathrm{\mu g} \mathrm{g}^{1}\right)$} & & \multicolumn{2}{|l|}{$\left.\mathrm{K}^{+}\left(\mu_{\mathrm{gg}}\right)^{-1}\right)$} & & \multicolumn{2}{|l|}{$\mathrm{Na}^{+} / \mathrm{K}^{+}$} & & \multicolumn{2}{|l|}{$\mathrm{Ca}^{2+}\left(\mathrm{Hg} \mathrm{g}^{-1}\right)$} & \\
\hline & & Control & \begin{tabular}{|l|l|l|l} 
Stress \\
\end{tabular} & & Control & Stress & & Control & Stress & & Control & Stress & \\
\hline & & & & \begin{tabular}{|l|}
$p$-level \\
(control vs \\
stress)
\end{tabular} & & & \begin{tabular}{|l|l}
$p$-level \\
(control vs \\
stress)
\end{tabular} & & & $\begin{array}{l}\text {-level } \\
\text { (control vs } \\
\text { stress) }\end{array}$ & & & \begin{tabular}{|l|}
$p$-level \\
(control vs \\
stress)
\end{tabular} \\
\hline \multirow[t]{3}{*}{0} & Apical leaf & - & - & & \begin{tabular}{|l|l}
$49,935.5 \pm 3922.2$ \\
\end{tabular} & - & & - & - & & $2562.4 \pm 479.8$ & - & \\
\hline & Basal leaf & - & - & & $44,195.7 \pm 5828.3$ & - & & - & - & & $4068.9 \pm 610.9$ & - & \\
\hline & \begin{tabular}{|l}
$p$-level \\
(apical vs \\
basal)
\end{tabular} & & & & ns & & & & & & * & & \\
\hline \multirow[t]{4}{*}{18} & Apical leaf & $0.0 \pm 0.0$ & $7338.4 \pm 1124.1$ & $* * *$ & \begin{tabular}{|l|l}
$34,108.4 \pm 789.7$ \\
\end{tabular} & \begin{tabular}{|l|l}
$46,975.7 \pm 5582.3$ \\
\end{tabular} & * & $0.0 \pm 0.0$ & \begin{tabular}{|l|l|}
$0.48 \pm 0.03$ \\
\end{tabular} & $* * *$ & $1581.7 \pm 189.8$ & $2770.2 \pm 659.7$ & $* *$ \\
\hline & Basal leaf & \begin{tabular}{|l}
$1070.3 \pm 284.4$ \\
\end{tabular} & $7033.4 \pm 216.6$ & $* * *$ & \begin{tabular}{|l|l}
$30,336.0 \pm 1680.7$ \\
\end{tabular} & $33,284.7 \pm 6036.5$ & ns & \begin{tabular}{|l|l|}
$0.11 \pm 0.01$ \\
\end{tabular} & \begin{tabular}{|l|l|}
$0.66 \pm 0.04$ \\
\end{tabular} & ** & \begin{tabular}{|l|l|}
$7418.6 \pm .1$ \\
\end{tabular} & $6441.9 \pm 1199.0$ & * \\
\hline & \begin{tabular}{|l}
$p$-level \\
(apical vs \\
basal)
\end{tabular} & $\ldots * *$ & ns & & ns & ns & & *** & * & & 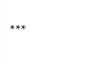 & * & \\
\hline & Apical leaf & $0.0 \pm 0.0$ & \begin{tabular}{|l|l|}
$9024.3 \pm 0.5$ \\
\end{tabular} & $* * *$ & \begin{tabular}{|l|l}
$42,085.8 \pm 2140.0$ \\
\end{tabular} & $37,007.5 \pm 0.5$ & . & $0.0 \pm 0.0$ & \begin{tabular}{|l|l|}
$0.74 \pm 0.00$ \\
\end{tabular} & $* * *$ & $2735.7 \pm 413.2$ & $6364.3 \pm 0.0$ & $* * *$ \\
\hline \multirow[t]{2}{*}{24} & Basal leaf & $3939.4 \pm 789.4$ & $8829.3 \pm 501.8$ & $* * *$ & $36,123.7 \pm 3347.9$ & $44,650.0 \pm 1475.7$ & * & $0.32 \pm 0.01$ & $0.59 \pm 0.01$ & $* *$ & $8957.4 \pm 328.9$ & $5438.0 \pm 727.8$ & $* *$ \\
\hline & $\begin{array}{l}\text {-level } \\
\text { (apical vs } \\
\text { basal) }\end{array}$ & $\ldots *$ & ns & & ns & ns & & $\cdots$ & * & & 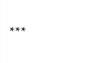 & * & \\
\hline
\end{tabular}

Table 2. Concentration of $\mathrm{Na}^{+}\left(\mu \mathrm{g} \mathrm{g}^{-1}\right), \mathrm{K}^{+}\left(\mu \mathrm{g} \mathrm{g}^{-1}\right)$ and $\mathrm{Ca}^{2+}\left(\mu \mathrm{g} \mathrm{g}{ }^{-1}\right)$ in control- and salt stressed. Arundo donax plants were measured at different sampling times: in the initial phase ( $0 \mathrm{dpi})$, in the median phase (18 dpi), and in the final phase $(24 \mathrm{dpi})$. Values represent the mean \pm standard errors $(\mathrm{n}=4)$. ANOVA was reported to assess statistical differences between control and salt-stressed plants and between apical and basal leaf level $\left({ }^{* *} p \leq 0.001 ;{ }^{* *} p \leq 0.01 ;{ }^{*} p \leq 0.05\right.$; ns, not significant). 


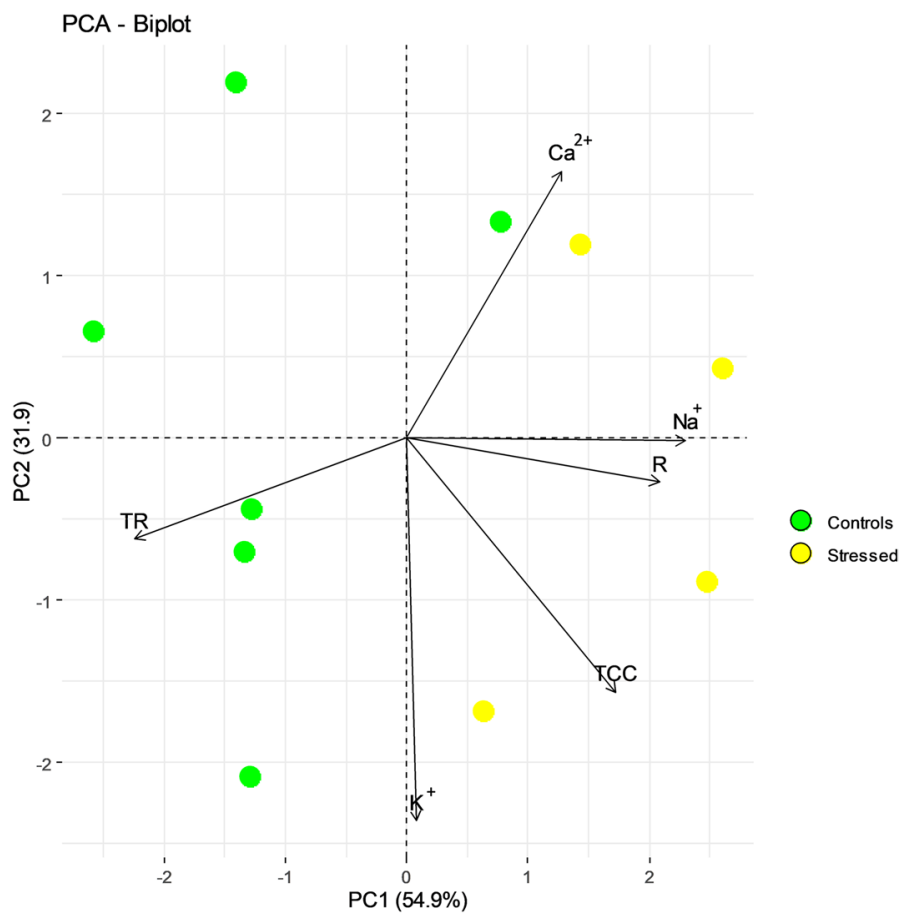

Figure 5. Biplot of the PCA results. The first two PCs display $86.8 \%$ of the total physiological variation. The component scores are coloured according to the agronomic groups (yellow dots, stressed plants; green dots control plants). The components loading vectors were proportionally superimposed to their contribution, and their direction indicated the influence of variable group. R, bioristor Response; $\mathrm{Na}^{+}$, sodium concentration; $\mathrm{K}^{+}$, potassium concentration; $\mathrm{Ca}^{2+}$, calcium concentration and TCC, total cations concentration measured in Arundo leaves; TR, transpiration rate.

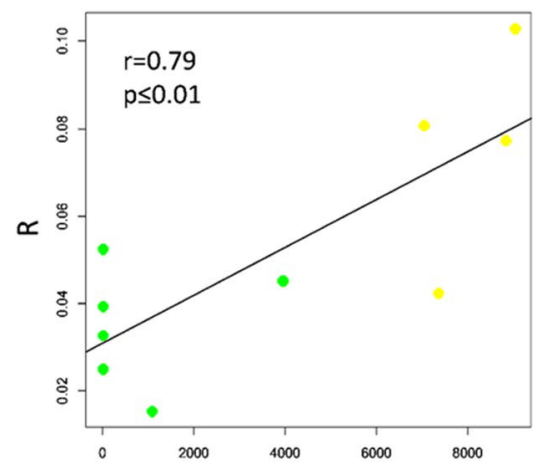

A)

$\mathrm{Na}^{+}$Concentration $(\mu \mathrm{g} / \mathrm{g})$

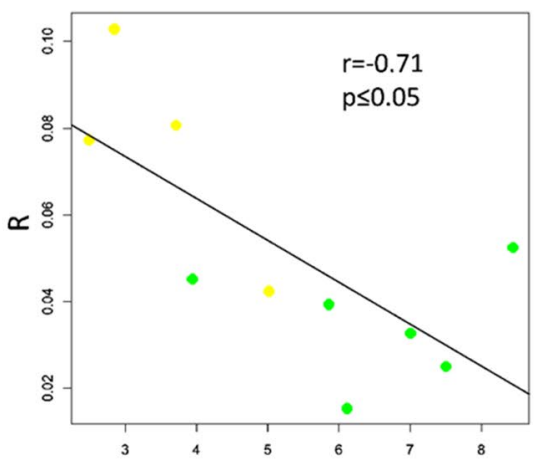

B)

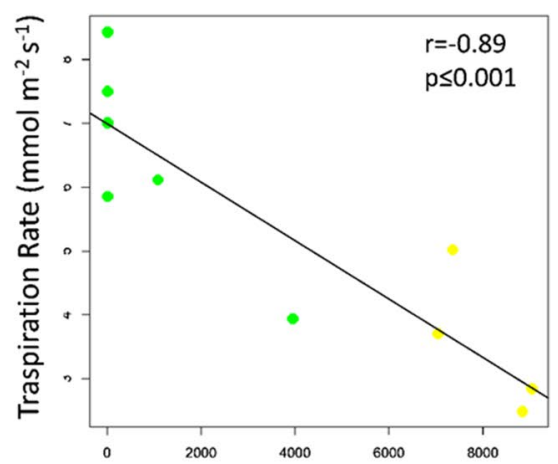

C)

Figure 6. Scatter plots showing the high correlation observed between: the sensor response, $\mathrm{R}$, and $\mathrm{Na}^{+}$concentration measured in leaves $(\mathbf{A})$ and transpiration rate, TR, $(\mathbf{B})$, and between transpiration rate and $\mathrm{Na}^{+}$concentration $(\mathbf{C})$. Green dots indicate the control plants, yellow dots the stressed plants. Pearson correlation coefficient $(\mathrm{r})$ was reported to indicate the statistical significance of observed correlations $(p \leq 0.05)$.

Plants have been categorized according to their ability to overcome salt stress: (1) the ability of a plant to survive on saline soils; (2) the absolute plant growth; and (3) the relative growth on saline soil compared to growth on non-saline soils ${ }^{19,37}$.

Here a bioelectronics approach was used to investigate the ability of $A$. donax to growth under adverse growing conditions as high soil salinity exploiting organic chemistry that enables design and tailoring of active materials with desired characteristics, such as functionality, processability, and biocompatibility.

Organic bioelectronics devices and materials have been applied mainly in the context of light-emitting and photovoltaic devices, stretchable and wearable devices, and biomedical applications. However, its usefulness and applicability in plants to monitor and control plant physiology has begun to be explored ${ }^{26,38-42}$. Its use will 


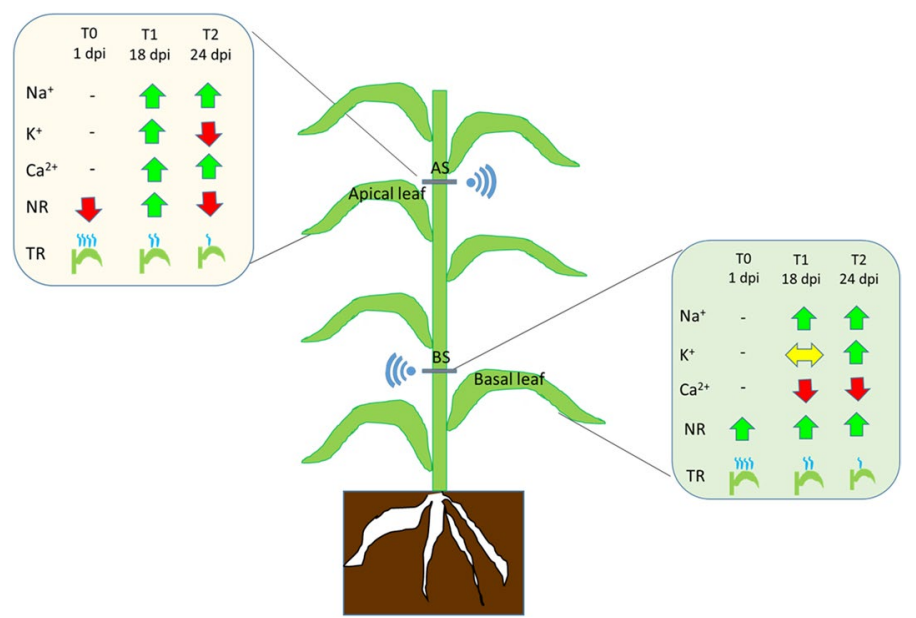

Figure 7. Qualitative visualisation of the bioristor (NR, normalized sensor response); TR, (transpiration rate) and plant ions concentration $\left(\mathrm{Na}^{+}\right.$, sodium; $\mathrm{K}^{+}$, potassium; $\mathrm{Ca}^{2+}$, calcium) measured in leaves.

enhance the possibility to have a continuous monitoring of the physiological processes occurring during the plant growth and upon environmental stress, having a wider picture of the ongoing responses.

Conventionally, punctual detection of the physiological status of plants, a range of technologies and/or their combinations have been applied ${ }^{43-45}$, such as electrical impedance spectroscopy (EIS) ${ }^{24,25}$, chlorophyll fluorescence imaging $^{46,47}$, multispectral imaging ${ }^{48}$, thermal imaging ${ }^{49}$ and electric signals ${ }^{50}$.

Here, an in vivo OECT based sensor, namely bioristor, has been inserted into the stem of the plant. The physiological effects of salt application in Arundo donax have been monitored and the ability of bioristor to return a salt stress specific response has been demonstrated. Moreover, being an OECT, the sensor response of the bioristor allows a measurement of the total cation concentration within the plant $\mathrm{t}^{30-33}$. An increased NR in both BS and AS (Fig. 3) and linear correlation between $\mathrm{R}$ and the concentration of cations clearly indicated that the bioristor can effectively reveal presence and changes of all cations in the plant sap. Indeed, $\mathrm{R}$ is consistent with the daily transpiration trend due to light-driven stomatal opening and the consequent onset of transpirative passive flux from the soil to the air $^{51}$. Plant growth and development relies on the movement of various ions through the plant sap ${ }^{52}$. The observed circadian variation in sap electrical conductivity of $A$. donax was consistent with the long-distance transport of solutes through the xylem. In fact, ion concentrations are typically higher during the night than in the day ${ }^{53}$ when they are diluted by the higher water transpiration stream ${ }^{26}$.

Absence of changes in normalized response (NR) values of apical sensor (AS) during the initial stage of the salt treatments (4-6 dpi), may indicate that $\mathrm{Na}^{+}$mainly accumulate in basal leaves of $A$. donax (and it does not reach the apical ones) during the first days upon the treatment (4-6 dpi), despite these data are not supported by quantitative data on ions concentration in leaves. Overall, our results support a positive ion compartmentalization, namely of $\mathrm{Na}^{+}$, in the basal portion of the plant during the early phases of the saline stress, following the addition of $\mathrm{NaCl}$ to the substrate (Fig. 7). Moreover, the ion transport was described by the NR as follow: the basal sensor (BS) continuously detected a different and higher number of positive ions at lower rate, whereas the upper leaves showed that higher values of ions occurred at a later stage of salinity stress (14 dpi).

When compared with in vivo assessment of leaf transpiration, the bioristor showed a similar trend with the transpiration rate enabling to trace the plant transpiration throughout the measurements of the ions dissolved in the plant sap in the transpiration stream (Fig. 7).

This last result, further support the ability of biostor to detect ions and molecules dissolved and transported through the transpiration stream, suggesting the sensor response as a good proxy of transpiration.

High-resolution sensors are powerful tools to investigate promptly plant responses. In this study case, the bioristor highlighted the potential to synchronize plant functions and environment variations in time series, by providing a continuously monitoring in real-time of the dynamic changes.

The lower transpiration rate (TR) in salt-stressed plants than in control ones and the higher TR in the apical than in basal leaves of salt-stressed plants were expected as root absorption of $\mathrm{Na}^{+}$enhanced the synthesis of Abscisic acid (ABA) that causes a prompt stomatal closure and thus limits transpiration ${ }^{54,55}$. However, the toxic accumulation of $\mathrm{Na}^{+}$and the enhancement of both $\mathrm{K}^{+}$uptake and accumulation imply that $\mathrm{Na}^{+}$and $\mathrm{K}^{+}$ transporters and channels play a major role in salt stress tolerance ${ }^{56}$.

The combination of sensors applied in the apical and basal plant parts allowed to hypothesize the trend in time and space of ions or positive electrolytes transport along the culm. The application of the bioristor to $A$. donax plants revealed an initial compartmentalization of the $\mathrm{Na}^{+}, \mathrm{K}^{+}$and $\mathrm{Ca}^{2+}$ ions into the basal leaves during the early stages salt stress, whereas $\mathrm{Na}^{+}$reaches the apical leaves at later stages of the salt stress.

In addition, PCA suggests the sodium uptake as major driver of the variation in the sensor responses between stressed and control plants. This is also supported by the increased $\mathrm{Na}^{+}$concentration measured in treated leaves versus the controls with respect to the other ions measured (Table 2). 
The effects of electrical signal in the ion uptake and flow in the plant xylem have been also reported ${ }^{57,58}$ and extensively review in terms of plant physiology and root phenotyping ${ }^{23,58,59}$. Here, we assume as neutral the contribution of the plant sap electronic signal on the bioristor sensor response based on the OECT working principle. This is based on doping-state changes in the semiconductor channel material (PEDOT: PSS) due to electrolyte-ion injections which modify the electrical conductivity ${ }^{28}$. Ions can diffuse through the electrolyte due to electrostatic repulsion and penetrate the polymer matrix thanks to the application of a gate voltage selectively applied $(\mathrm{Vg})$ that controls the infiltration of ions into the channel and, consequently, the material's doping extent/degree (redox state). The extent of the reduction of the channel current is measured in the time window relative to the application of the gate voltage $(6 \mathrm{~min})$ and is, thus, strictly dependent on the ions concentration in the electrolyte solution in the OECT geometry $(0,5-1 \mathrm{~cm}$ between the gate and the channel of the OECT). To support this hypothesis, we observed that if the voltage applied to the gate is $0 \mathrm{~V}$, the sensor response $\mathrm{R}$ is also 0 , excluding any interference of electrophysiology signals in the sensor response.

The ongoing development and application of a bioristor functionalized with ion-selective membranes, will further help in deciphering the mechanisms occurring in the ion movements in saline stress conditions ${ }^{60}$.

The application of the bioristor on several plant species and its development for the ion specific detection can significantly improve in vivo plant phenotyping and the real-time monitoring of salt stress for the identification of salt resilient genotypes.

The high sensitivity of bioristor and in general of OECT sensors towards physiological changes occurring in the plant sap, supports the effectiveness of bioristor as tool for in vivo phenotyping studies and precision agriculture to bridge electronics and biological systems.

\section{Methods}

Plant material and salt $(\mathrm{NaCl})$ stress application. A. donax plants were propagated by rhizomes collected in Sesto Fiorentino $\left(43^{\circ} 81^{\prime} 75^{\prime \prime} \mathrm{N}, 11^{\circ} 18^{\prime} 88^{\prime \prime} \mathrm{E}\right.$ ) (Italy). Rhizomes were kept in tap water for one day before to be planted in $6 \mathrm{~L}$ pots containing quartz sand (substrate). Plants were obtained from rhizomes in two months and then kept growing in a climatic chamber under controlled environmental conditions: maximum and minimum (day/night) temperature of $30{ }^{\circ} \mathrm{C}$ and $22{ }^{\circ} \mathrm{C}$, respectively; maximum and minimum relative air humidity of $60 \%$ and $40 \%$, respectively; photosynthetic photon flux density (PPFD) of $700 \mu \mathrm{mol} \mathrm{m} \mathrm{m}^{-2} \mathrm{~s}^{-1}$ for 14 h per day. Plants were watered weekly with full strength Hoagland solution in order to supply mineral nutrients to optimal level until the beginning of the experiment.

The experiment was performed by growing two different groups of $10 \mathrm{~A}$. donax plants: (a) under optimal nutritional conditions by applying the standard Hoagland solution (control); (b) by applying Hoagland solution where $200 \mathrm{mM} \mathrm{NaCl}\left(\mathrm{Na}^{+}\right.$salt stress) were added. These solutions were supplied twice a week; the treatment lasted 37 days (Fig. 1A).

Bioristor: sensor description, data acquisition and analysis. The bioristor is an Organic Electrochemical Transistor (OECT) whose channel and gate electrodes, both constituted by a textile fiber functionalized with a conductive polymer ${ }^{31}$, were directly integrated into the plant stem (Fig. 1B). For the functionalization, two textile fibers were soaked for $5 \mathrm{~min}$ in aqueous poly(3,4-ethylenedioxythiophene) doped with polystyrene sulfonate (CleviosPH500, Starck GmbH, Munich, Germany), after which ethylene glycol (10\% v/v) and dodecyl benzene sulfonic acid ( $2 \% \mathrm{v} / \mathrm{v})$ were added. The fibers were then baked at $130^{\circ} \mathrm{C}$ for $90 \mathrm{~min}$. Before functionalization, each thread was cleaned with a plasma oxygen cleaner treatment (Femto, Diener electronic, Ebhausen/Germany) to increase its wettability and facilitate the adhesion of the aqueous conductive polymer solution. A treated fiber was inserted into the stem of each $A$. donax plant, until it passed to the opposite side of the stem. The fiber was connected on each end to a metal wire with silver paste to stabilize the connections, forming the "source" and "drain" electrodes. The transistor device was completed by introducing a second functionalized textile thread as the gate electrode to reduce the drawback effects caused by the silver wire used for tomato plants ${ }^{26}$. The bioristor elements were connected to a NI USB-6343 multifunction I/O device (National Instruments, Austin, TX, USA) (Fig. 1).

The bioristor drain and gate current play a major role in determining the sensor response. The p-type doped PEDOT (oxidized from the electrochemistry point of view) leads to mobile holes generating a hole current $\left(\mathrm{I}_{\mathrm{ds} 0}\right)$ which flows in the channel when a drain voltage $\left(\mathrm{V}_{\mathrm{ds}}=-0.05 \mathrm{~V}\right)$ is applied. These holes are balanced by the negative charge of the PSS sulfonate group ${ }^{61}$, until the application of a positive gate bias $\left(\mathrm{V}_{\mathrm{gs}}=0.6 \mathrm{~V}\right)$, which leads to the injection of cations $\left(\mathrm{M}^{+}\right)$from the electrolyte (xylem sap in this case) into the PEDOT: PSS channel causing its de-doping, according to equation ${ }^{62}$ :

$$
\text { PEDOT }^{+}: \mathrm{PSS}^{-}+\mathrm{M}^{+}+\mathrm{e}^{-} \rightarrow \mathrm{PEDOT}^{0}+\mathrm{M}^{+}: \mathrm{PSS}^{-}
$$

The "de-doping process" ${ }^{3}$, according to the reduction of the oxidized $\mathrm{PEDOT}^{+}$to $\mathrm{PEDOT}^{0}$ and the decrease of the number of holes in the channel, leads to a drop in the drain current $\left(\mathrm{I}_{\mathrm{ds}}\right)$. The whole process is reversible: when gate-source voltage is switched off $\left(\mathrm{V}_{\mathrm{gs}}=0 \mathrm{~V}\right)$, cations diffuse from the channel to the electrolyte increasing the number of conducting holes and, consequently reduced $\mathrm{PEDOT}^{0}$ returns to the oxidized state and drainsource current to the initial value $\left(\mathrm{I}_{\mathrm{ds} 0}\right)$. During the entire experiment, the $0.6 \mathrm{~V}$ gate-source voltage is turned on for $6 \mathrm{~min}$ and then it is turned off; the measurement is repeated every $24 \mathrm{~min}$.

The sensor response (R), obtained every $24 \mathrm{~min}$, can be expressed as

$$
\mathrm{R}=\left|\mathrm{I}_{\mathrm{dS}}-\mathrm{I}_{\mathrm{dS} 0}\right| / \mathrm{I}_{\mathrm{dS} 0}
$$


where Ids is the value of the drain current just before the gate-source voltage is turned off. $\mathrm{R}$ is related to the cation concentration in the electrolyte solution ${ }^{22}$, thus allowing the monitoring of the temporal variation in the plant sap's cationic content. Here, $R$ measured in stressed plants $\left(\mathrm{R}_{\text {stress }}\right)$ and in control plants $\left(\mathrm{R}_{\text {control }}\right)$ is reported.

When monitoring the plant sap concentration over several days it showed to be useful to smooth out the day/night signal oscillations due to plant circadian rhythms that characterize the bioristor response ${ }^{19}$. Thus, the ratio between the signal recorded form sensors installed in salt-stressed and control plants was expressed as Normalized Response (NR);

$$
\mathrm{NR}=\mathrm{R}_{\text {stress }} / \mathrm{R}_{\text {control }}
$$

To investigate the possibility to track the ion transport (in specific of the $\mathrm{Na}^{+}$ion) along the plant culms of A. donax plants, two bioristor sensors were integrated at two different heights along the same culm, the apical sensor (AS) between the 2nd and 3rd leaf and the basal sensor (BS) between the 5th and 6th leaf from the apex (Fig. 1C) in 3 control and 3 salt-stressed $A$. donax plants (for a total of 12 sensors). From the overall data acquired (37 days), three intervals, defined from the day of installation (dpi; 1-7 dpi; 13-19 dpi; 27-37 dpi) have been selected as the most representative of the entire set of measurements due to both their low background noise and accuracy which have been indicated as initial (1-7 dpi), median (13-19 dpi) and final (27-32 dpi) phase. The median and final phases began with a sensor maintenance causing a variation in the recorded values due to the new sensor's part integration. Therefore, these three intervals should be read as independent measurements and therefore the moving average of the NR was evaluated for each of those.

The operability of the bioristor was validated within the range of sodium $\left(\mathrm{Na}^{+}\right)$, calcium $\left(\mathrm{Ca}^{2+}\right)$ and potassium $\left(\mathrm{K}^{+}\right)$concentrations detected in the leaves; the sensor response was measured in vitro by using different solutions at low concentrations of $\mathrm{Na}^{+}(0.01$ to $0.19 \mathrm{M}), \mathrm{K}^{+}(0.2$ to $0.8 \mathrm{M})$, and $\mathrm{Ca}^{2+}(0.01-0.1 \mathrm{M})$. Moreover, the sensor response was evaluated as $\mathrm{V}_{\mathrm{ds}}=-0.05 \mathrm{~V}$ and $\mathrm{V}_{\mathrm{gs}}$ in the $0-1 \mathrm{~V}$ voltage range using $0.2 \mathrm{~V}$ steps. Transfer characteristics are expressed as Sensor Response (R) vs $\mathrm{V}_{\mathrm{gs}}$.

Plant physiological response to salinity. The transpiration flux of $\mathrm{H}_{2} \mathrm{O}$ (TR) was measured in vivo in the 2 nd and 5 th leaf (from the shoot apex) of $A$. donax plants by using a portable gas exchange system ( $\mathrm{Li}$-Cor 6400, Li-Cor Biosciences Inc., NE, USA). A portion of leaf was clamped in the $2 \mathrm{~cm}^{2} \mathrm{Li}$-Cor cuvette and exposed to a constant PPFD of $1000 \mu \mathrm{mol} \mathrm{m}{ }^{-2} \mathrm{~s}^{-1}, \mathrm{CO}_{2}$ concentration of $400 \mathrm{ppm}$, temperature of $30{ }^{\circ} \mathrm{C}$ and relative humidity (RH) ranging between 45 and 50\%. After reaching steady-state conditions, TR and PR were calculated according to the formulations of von Caemmerer et al. ${ }^{64}$. Analysis was performed in leaves sampled at different days post insertion (dpi) of the sensor: $1 \mathrm{dpi}, 14 \mathrm{dpi}, 24 \mathrm{dpi}$.

The concentrations of $\mathrm{Na}^{+}, \mathrm{Ca}^{2+}$ and $\mathrm{K}^{+}\left(\mu \mathrm{g} \mathrm{g} \mathrm{g}^{-1} \mathrm{DW}\right)$ accumulated in A. donax plants were determined in $1 \mathrm{~g}$ of leaves by flame atomic absorption spectrometry (Analyst 200, Perkin Elmer). Analysis of these mineral elements was performed in the same leaves following gas exchange measurements.

Statistical analyses. All data retrieved from the sensors were statistically analysed by applying a multicomparison approach using the Analysis of Variance (ANOVA) in MatLab 2014a (8.3.0.532). Principal components analyses (PCA) was performed using the R "prcomp" function and represented as a biplot by using the $\mathrm{R}$ package factoextra ${ }^{65,66}$. The first two principal components PC1 and PC2 and the corresponding component loading vectors were visualized and summarized in a biplot, in which component scores (indicated in dots) are coloured according to thesis classification. Analysis of variance (ANOVA) was performed to assess the effect of $\mathrm{Na}^{+}$supply in $A$. donax plants ( $p \leq 0.05$ level).

\section{Data availability}

The data supporting the findings of this study are available from the corresponding authors upon request.

Received: 27 August 2020; Accepted: 24 August 2021

Published online: 20 September 2021

\section{References}

1. Liang, W., Ma, X., Wan, P. \& Liu, L. Plant salt-tolerance mechanism: A review. Biochem. Biophys. Res. Commun. 495, $286-291$. https://doi.org/10.1016/j.bbrc.2017.11.043 (2018).

2. Yang, Y. \& Guo, Y. Elucidating the molecular mechanisms mediating plant salt-stress responses. New Phytol. 217, 523-539. https:// doi.org/10.1111/nph.14920 (2018).

3. FAO, FAO SOILS PORTAL, Httpwwwfaoorgsoils-Portalen. (2018). http://www.fao.org/soils-portal/en/. Accessed December 17, 2018.

4. Hanin, M., Ebel, C., Ngom, M., Laplaze, L. \& Masmoudi, K. New insights on plant salt tolerance mechanisms and their potential use for breeding. Front. Plant Sci. https://doi.org/10.3389/fpls.2016.01787 (2016).

5. R. Vargas Rojas, E.I. Pankova, S.A. Balyuk, P.K. Krasil'nikov, G.M. Khasankhanova, Food and Agriculture Organization of the United Nations, Moskovskiı̌ gosudarstvennyı̆ universitet im. M.V. Lomonosova, Handbook for saline soil management, 2018. http://www.fao.org/3/i7318en/I7318EN.pdf. Accessed September 17, 2019.

6. Munns, R. \& Tester, M. Mechanisms of salinity tolerance. Annu. Rev. Plant Biol. 59, 651-681. https://doi.org/10.1146/annurev. arplant.59.032607.092911 (2008).

7. Munns, R., Passioura, J. B., Colmer, T. D. \& Byrt, C. S. Osmotic adjustment and energy limitations to plant growth in saline soil. New Phytol. https://doi.org/10.1111/nph.15862 (2019).

8. Negrão, S., Schmöckel, S. M. \& Tester, M. Evaluating physiological responses of plants to salinity stress. Ann. Bot. 119, 1-11. https:// doi.org/10.1093/aob/mcw191 (2017).

9. Hairmansis, A., Berger, B., Tester, M. \& Roy, S. J. Image-based phenotyping for non-destructive screening of different salinity tolerance traits in rice. Rice 7, 16 (2014). 
10. Nackley, L. L. \& Kim, S.-H. A salt on the bioenergy and biological invasions debate: salinity tolerance of the invasive biomass feedstock Arundo donax. GCB Bioenergy. 7, 752-762. https://doi.org/10.1111/gcbb.12184 (2015).

11. Romero-Aranda, R., Soria, T. \& Cuartero, J. Tomato plant-water uptake and plant-water relationships under saline growth conditions. Plant Sci. 160, 265-272 (2001).

12. Tyerman, S. D. et al. Energy costs of salinity tolerance in crop plants. New Phytol. 221, 25-29. https://doi.org/10.1111/nph.15555 (2019).

13. Zhou, R. et al. Drought stress had a predominant effect over heat stress on three tomato cultivars subjected to combined stress. BMC Plant Biol. https://doi.org/10.1186/s12870-017-0974-x (2017).

14. Cocozza, C. et al. The excess of phosphorus in soil reduces physiological performances over time but enhances prompt recovery of salt-stressed Arundo donax plants. Plant Physiol. Biochem. 151, 556-565. https://doi.org/10.1016/j.plaphy.2020.04.011 (2020).

15. B. Berger, B. de Regt, M. Tester, Trait Dissection of Salinity Tolerance with Plant Phenomics, in: S. Shabala, T.A. Cuin (Eds.), Plant Salt Toler., Humana Press, Totowa, NJ, 2012: pp. 399-413. https://doi.org/10.1007/978-1-61779-986-0_27.

16. Costa, C., Schurr, U., Loreto, F., Menesatti, P. \& Carpentier, S. Plant phenotyping research trends, a science mapping approach. Front. Plant Sci. https://doi.org/10.3389/fpls.2018.01933 (2019).

17. Fahlgren, N., Gehan, M. A. \& Baxter, I. Lights, camera, action: High-throughput plant phenotyping is ready for a close-up. Curr. Opin. Plant Biol. 24, 93-99. https://doi.org/10.1016/j.pbi.2015.02.006 (2015).

18. R. Pieruschka, U. Schurr, Plant Phenotyping: Past, Present, and Future, Plant Phenomics. 7507131 (2019). https://doi.org/10.34133/ 2019/7507131.

19. Tripodi, P., Massa, D., Venezia, A. \& Cardi, T. Sensing technologies for precision phenotyping in vegetable crops: Current status and future challenges. Agronomy 8, 57. https://doi.org/10.3390/agronomy8040057 (2018).

20. Clausen, C. \& Dixon, T. E. Membrane electrical parameters in turtle bladder measured using impedance-analysis techniques. J. Membr. Biol. 92, 9-19. https://doi.org/10.1007/BF01869011 (1986).

21. Zhang, M. I. N. \& Willison, J. H. M. Electrical impedance analysis in plant tissues11. J. Exp. Bot. 42, 1465-1475. https://doi.org/ $10.1093 / \mathrm{jxb} / 42.11 .1465$ (1991).

22. Mancuso, S. Seasonal dynamics of electrical impedance parameters in shoots and leaves related to rooting ability of olive (Olea europea) cuttings. Tree Physiol. 19, 95-101. https://doi.org/10.1093/treephys/19.2.95 (1999).

23. Jócsák, I., Végvári, G. \& Vozáry, E. Electrical impedance measurement on plants: A review with some insights to other fields. Theor. Exp. Plant Physiol. 31, 359-375. https://doi.org/10.1007/s40626-019-00152-y (2019).

24. Ben Hamed, K., Zorrig, W. \& Hamzaoui, A. H. Electrical impedance spectroscopy: A tool to investigate the responses of one halophyte to different growth and stress conditions. Comput. Electron. Agric. 123, 376-383. https://doi.org/10.1016/j.compag. 2016.03.006 (2016).

25. Jamaludin, D., Abd Aziz, S., Ahmad, D. \& Jaafar, H. Z. E. Impedance analysis of Labisia pumila plant water status. Inf. Process. Agric. 2, 161-168. https://doi.org/10.1016/j.inpa.2015.07.004 (2015).

26. Coppedè, N. et al. An in vivo biosensing, biomimetic electrochemical transistor with applications in plant science and precision farming. Sci. Rep. 7, 16195. https://doi.org/10.1038/s41598-017-16217-4 (2017).

27. Bernards, D. A. et al. Enzymatic sensing with organic electrochemical transistors. J. Mater. Chem. 18, 116-120. https://doi.org/10. 1039/B713122D (2008).

28. Marquez, A. V., McEvoy, N. \& Pakdel, A. Organic electrochemical transistors (OECTs) toward flexible and wearable bioelectronics. Molecules 25, 5288. https://doi.org/10.3390/molecules25225288 (2020).

29. Friedlein, J. T., Donahue, M. J., Shaheen, S. E., Malliaras, G. G. \& McLeod, R. R. Microsecond response in organic electrochemical transistors: exceeding the ionic speed limit. Adv. Mater. 28, 8398-8404. https://doi.org/10.1002/adma.201602684 (2016).

30. Coppedè, N. et al. Introducing state variables in Organic Electrochemical Transistors with application to biophysical systems. IEEE Sens. J. https://doi.org/10.1109/JSEN.2019.2940993 (2019).

31. Tarabella, G. et al. A single cotton fiber organic electrochemical transistor for liquid electrolyte saline sensing. J. Mater. Chem. 22, 23830. https://doi.org/10.1039/c2jm34898e (2012).

32. Iannotta, S., D’Angelo, P., Romeo, A. \& Tarabella, G. Scalable and flexible bioelectronics and its applications to medicine, large area flex. Electron. https://doi.org/10.1002/9783527679973.ch18 (2015).

33. Janni, M. et al. In vivo phenotyping for the early detection of drought stress in tomato. Plant Phenom. https://doi.org/10.34133/ 2019/6168209 (2019).

34. Vurro, F. et al. Development of an in vivo sensor to monitor the effects of vapour pressure deficit (VPD) changes to improve water productivity in agriculture. Sensors. 19, 4667. https://doi.org/10.3390/s19214667 (2019).

35. R. Pilu, A. Bucci, F.C. Badone, M. Landoni, Giant reed (Arundo donax L.): A weed plant or a promising energy crop? (2012). https:// doi.org/10.5897/ajb11.4182.

36. Pompeiano, A. et al. Allocation pattern, ion partitioning, and chlorophyll a fluorescence in Arundo donax L. in responses to salinity stress. Plant Biosyst. Int. J. Deal. Asp. Plant Biol. 151, 613-622. https://doi.org/10.1080/11263504.2016.1187680 (2017).

37. Maas, E. V., Poss, J. V. \& Hoffman, G. J. Salt tolerance of plants. Appl. Agric. Res. 1, 12-26 (1986).

38. Rivnay, J. et al. Organic electrochemical transistors. Nat. Rev. Mater. 3, 17086. https://doi.org/10.1038/natrevmats.2017.86 (2018).

39. Bernacka-Wojcik, I. et al. Implantable organic electronic ion pump enables ABA hormone delivery for control of stomata in an intact tobacco plant. Small 15, 1902189. https://doi.org/10.1002/smll.201902189 (2019).

40. C. Diacci, T. Abedi, J. Lee, E.O. Gabrielsson, M. Berggren, D.T. Simon, T. Niittylä, E. Stavrinidou, Diurnal In Vivo Xylem Sap Glucose and Sucrose Monitoring Using Implantable Organic Electrochemical Transistor Sensors, Social Science Research Network, Rochester, NY, (2020). https://doi.org/10.2139/ssrn.3699789.

41. Poxson, D. J. et al. Regulating plant physiology with organic electronics. Proc. Natl. Acad. Sci. U. S. A. 114, 4597-4602. https://doi. org/10.1073/pnas.1617758114 (2017).

42. Brotchie, A. Plant physiology: Organic electronics take root. Nat. Rev. Mater. 2, 1-1. https://doi.org/10.1038/natrevmats.2017.32 (2017).

43. Zhao, C. et al. Crop phenomics: Current status and perspectives. Front. Plant Sci. https://doi.org/10.3389/fpls.2019.00714 (2019).

44. Li, L., Zhang, Q. \& Huang, D. A review of imaging techniques for plant phenotyping. Sensors. 14, 20078-20111. https://doi.org/ $10.3390 / \mathrm{s} 141120078(2014)$.

45. Atkinson, J. A., Jackson, R. J., Bentley, A. R., Ober, E. \& Wells, D. M. Field phenotyping for the future. Annu. Plant Rev. Online Am. Cancer Soc. https://doi.org/10.1002/9781119312994.apr0651 (2018).

46. Barbagallo, R. P., Oxborough, K., Pallett, K. E. \& Baker, N. R. Rapid, noninvasive screening for perturbations of metabolism and plant growth using chlorophyll fluorescence imaging. Plant Physiol. 132, 485-493. https://doi.org/10.1104/pp.102.018093 (2003).

47. Rosenqvist, E., Großkinsky, D. K., Ottosen, C.-O. \& van de Zedde, R. The phenotyping dilemma-The challenges of a diversified phenotyping community. Front. Plant Sci. 1, 1. https://doi.org/10.3389/fpls.2019.00163 (2019).

48. Lowe, A., Harrison, N. \& French, A. P. Hyperspectral image analysis techniques for the detection and classification of the early onset of plant disease and stress. Plant Methods https://doi.org/10.1186/s13007-017-0233-z (2017).

49. Still, C. et al. Thermal imaging in plant and ecosystem ecology: Applications and challenges. Ecosphere. 10, e02768. https://doi. org/10.1002/ecs2.2768 (2019).

50. Tran, D. et al. Electrophysiological assessment of plant status outside a Faraday cage using supervised machine learning. Sci. Rep. 9, 17073. https://doi.org/10.1038/s41598-019-53675-4 (2019). 
51. A. Johnsson, Oscillations in Plant Transpiration, in: S. Mancuso, S. Shabala (Eds.), Rhythms Plants Phenomenol. Mech. Adapt. Significance, Springer, Berlin, Heidelberg, 2007: pp. 93-113. https://doi.org/10.1007/978-3-540-68071-0_5.

52. Herdel, K., Schmidt, P., Feil, R., Mohr, A. \& Schurr, U. Dynamics of concentrations and nutrient fluxes in the xylem of Ricinus communis-diurnal course, impact of nutrient availability and nutrient uptake. Plant Cell Environ. 24, 41-52. https://doi.org/10. 1046/j.1365-3040.2001.00655.x (2001).

53. K. Mengel, E.A. Kirkby, Principles of Plant Nutrition, 5th ed., Springer Netherlands, (2001). https://doi.org/10.1007/ 978-94-010-1009-2.

54. Wilkinson, S. \& Davies, W. J. Manipulation of the apoplastic $\mathrm{pH}$ of intact plants mimics stomatal and growth responses to water availability and microclimatic variation. J. Exp. Bot. 59, 619-631. https://doi.org/10.1093/jxb/erm338 (2008).

55. Seiler, C. et al. Abscisic acid flux alterations result in differential abscisic acid signaling responses and impact assimilation efficiency in barley under terminal drought stress. Plant Physiol. 164, 1677-1696. https://doi.org/10.1104/pp.113.229062 (2014).

56. Assaha, D. V. M., Ueda, A., Saneoka, H., Al-Yahyai, R. \& Yaish, M. W. The role of Na+ and K+ transporters in salt stress adaptation in glycophytes. Front. Physiol. https://doi.org/10.3389/fphys.2017.00509 (2017).

57. Canales, J., Henriquez-Valencia, C. \& Brauchi, S. The integration of electrical signals originating in the root of vascular plants. Front. Plant Sci. https://doi.org/10.3389/fpls.2017.02173 (2018).

58. Peruzzo, L. et al. Imaging of plant current pathways for non-invasive root Phenotyping using a newly developed electrical current source density approach. Plant Soil. 450, 567-584. https://doi.org/10.1007/s11104-020-04529-w (2020).

59. Hedrich, R., Salvador-Recatalà, V. \& Dreyer, I. Electrical wiring and long-distance plant communication. Trends Plant Sci. 21, 376-387. https://doi.org/10.1016/j.tplants.2016.01.016 (2016).

60. Coppedè, N. et al. Ion selective textile organic electrochemical transistor for wearable sweat monitoring. Org. Electron. 78, 105579. https://doi.org/10.1016/j.orgel.2019.105579 (2020).

61. A. Elschner, S. Kirchmeyer, W. Lovenich, U. Merker, K. Reuter, PEDOT: Principles and applications of an intrinsically conductive polymer, CRC Press, 2010.

62. Nilsson, D., Robinson, N., Berggren, M. \& Forchheimer, R. Electrochemical logic circuits. Adv. Mater. 17, 353-358. https://doi. org/10.1002/adma.200401273 (2005)

63. Bernards, D. A. \& Malliaras, G. G. Steady-state and transient behavior of organic electrochemical transistors. Adv. Funct. Mater. 17, 3538-3544. https://doi.org/10.1002/adfm.200601239 (2007).

64. von Caemmerer, S. \& Farquhar, G. D. Some relationships between the biochemistry of photosynthesis and the gas exchange of leaves. Planta 153, 376-387 (1981).

65. A. Kassambara, F. Mundt, factoextra: Extract and Visualize the Results of Multivariate Data Analyses, 2016. https://CRAN.R-proje ct.org/package $=$ factoextra, $\mathrm{R}$ package version 1.0.3

66. R Core Team, A language and environment for statistical computing, R Found. Stat. Comput. Vienna Austria. (2020). https:// www.R-project.org/.

\section{Acknowledgements}

The study was funded by research project "CROPSTRESS-System performance of non-food crops to drought stress: development of a plant ideotype", by the SIR2014 program of the Italian Ministry of University and Research (RBSI14VV35; Principal investigator: Claudia Cocozza). Moreover, the project was partially supported by Italian ministry of Agriculture RGV FAO (DM 10271, Principal investigator Michela Janni). The authors thanks ALSIA for their financial support for bioristor development by funding Filippo Vurro PhD scholarship.

\section{Author contributions}

M.J.: Conceptualization of the bioristor application, Formal analysis, Data Curation and Visualization, Writing original draft preparation, C.C.: Conceptualization of salt stress experiment, Methodology, Validation, Formal analysis, Data Curation and Visualization, Resources, Writing original draft preparation, F.B.: Conceptualization, Data curation, Investigation, Physiological measurement, Writing-review \& editing; S.P.: Investigation F.V.: Investigation, formal analyses, N.C.: Writing-Review \& Editing, M.B.: Bioristor data curation, D.C.: Visualization, F.L.: Supervision, Reviewing and Editing, A.Z.: Supervision, Reviewing and Editing.

\section{Competing interests}

The authors declare no competing interests. The authors declare that experimental research and field studies on Arundo donax, including the collection of plant material, complied with relevant institutional, national, and international guidelines and legislation.

\section{Additional information}

Supplementary Information The online version contains supplementary material available at https://doi.org/ 10.1038/s41598-021-97872-6.

Correspondence and requests for materials should be addressed to J.M. or C.C.

Reprints and permissions information is available at www.nature.com/reprints.

Publisher's note Springer Nature remains neutral with regard to jurisdictional claims in published maps and institutional affiliations.

Open Access This article is licensed under a Creative Commons Attribution 4.0 International License, which permits use, sharing, adaptation, distribution and reproduction in any medium or format, as long as you give appropriate credit to the original author(s) and the source, provide a link to the Creative Commons licence, and indicate if changes were made. The images or other third party material in this article are included in the article's Creative Commons licence, unless indicated otherwise in a credit line to the material. If material is not included in the article's Creative Commons licence and your intended use is not permitted by statutory regulation or exceeds the permitted use, you will need to obtain permission directly from the copyright holder. To view a copy of this licence, visit http://creativecommons.org/licenses/by/4.0/.

(C) The Author(s) 2021 